\title{
TRATAMIENTO DE LA TOS FERINA CON ERITROMICINA*
}

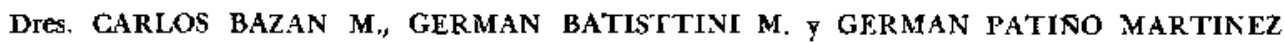

Cátedra de Puericultura y Pediatría del Prof. Carlos F. Krumdieck - Servicio de Infectocontagiosos. Hospital del Niño - Lima, Perú

Nadie ignora que en el tratamiento de la tos ferina, desde tiempos inmemoriales hasta la era de los antibióticos, se ha empleado el más variado arsenal terapéutico como en ninguna otra enfermedad de la infancia; $y$ sin embargo, las estadísticas demuestran una alta mortalidad en niños menores de $6 \mathrm{me}$ ses por el compromiso broncopulmonar propio de esta enfermedad. Si es verdad que con el empleo de Ios antibióticos se ha conseguido bajar en cifras apreciables los guarismos de letalidad, son harto discutibles las ventajas que existen entre ellos, cuando se trata de las complicaciones. $\mathrm{Y}$ es que hasta. el momento actual no se ha encontrado la medicación ideal, vale decir especítica.

Es así cómo resulta forzoso seguir empleando los mismos antibióticos a medida que van apareciendo $y$ que demuestran in vitro tener acción sobre el Hemophilus Pertussis, en la esperanza de mejorar los resultados de la estreptomicina, cloromicetina, terramicina $y$ aureomicina.

Alentados por la acción in vitro de la eritromicina sobre el germen y las facilidades que nos ha proporcionado la Casa Abbott, hemos emprendido el estudio clínico de un grupo de niños enfermos de coqueluche. cuyos resultados damos a conocer en el siguiente trabajo.

Sería largo enumerar los trabajos publicados que tratan sobre el empleo de los antibióticos en la tos ferina. Bástenos decir que en los últimos tiempos han sido ensayados todos Ios antibjóticos conocidos. Así GaIlafell Gilbert y Jufresa Roca (1953), en España, estudian el efecto de la cloromicetina y aureomicina (1) con resultados buenos en el $40 \%$ de los casos, usando el primero y con el $50 \%$ en el segundo. De Vito, en Italia (1950), da a conocer su impresión favorable acerca de la cloromicetina en 216 casos. Macrae, en Inglaterra (1950), es de la misma opinión. En Argentina, Canavari y Moscoso (1950) son partidarios de las ventajas de la cloromicetina. Payne y cols., en Bolivia (1950), tratan 50 nin̄os con cloromicetina con resultados espectaculares de curación entre el $3^{0}$ y $6^{\circ}$ día (2). En Chile, Julio Meneghello y Arturo Gallo (1951) tratan am- bulatoriamente 37 casos con cloromicetina y tienen la impresión de que es una droga útil, pero que las dosis y la duración del tratamiento deben ser revisadas (3).

Fn nuestro medio, Lozano enjuicia el estudio de la estreptomicina en su tesis de bachillerato del año 1947 (4). Hubí Campos (1950) emplea el aerosol de estreptomicina, con resultados favorables (5). Pozzi Escot (1951), en su tesis para bachiller se ocupa de la acción de la vitamina $\mathrm{K}$ (6). Valverde (1951) se ocupa en su tesis sobre la acción in vitro de la terramicina (7). Durán Lazarte (1951), en su tesis para bachiller se ocupa del tratamiento con la aureomicina con muy buenos resultados (8).

\section{Plan de estudio}

Como medida previa uno de nuestros colaboradores, el Dr. Germán Batisttini, ha comprobado la acción bacteriostática in vitro, de la eritromicina sobre el hemophilus pertussis fase 1 , acción que se ejerce desde una concentración que varía entre 0,1 y $0,5 \mathrm{mcg} / \mathrm{cm}$.a a $35^{\circ} \mathrm{C}$, en 48 horas.

Conociendo la acción evidente del antibiótico, in vitro, sobre el germen, se han seleccionado 20 niños entre $3 \frac{1}{2}$ meses y 10 años de edad, sin tratamiento alguno, en los cuales se ha tomado en ctenta la positividad del cultivo al hemophilus pertussis, el dato epidemiológico, una sintomatología que no admite discusión, como ser el carácter de las quintas y para mayor seguridad se ha excluido por los medios conocidos la tuberculosis y otras enfermedades que pueden confundirse con la coqueluche.

Para formarnos un juicio exacto acerca de la verdadera acción del antibiótico empleado, en las historias clínicas se ha seguido un control minucioso sobre las diversas modalidades clínicas (quintas, vómitos, decaimiento y recrudescencia) $\mathrm{y}$ hematológicas (leucocitosis, linfocitosis y velocidad de sedimentación), antes, durante $y$ después del tratamiento.

* Trabajo presentado a la Sociectad leruana de Pediatría en la sesión del día 19 de agosto de 1953. 
$Y$ para sentar conclusiones se ha seguido observando a los enfermos durante un mes después del tratamiento, con el fín de pesquisar la reagudización de los síntomas.

Eritromicina. Es un nuevo antibiótico cristalino producido durante el desarrollo del Streptomyces Erithreus. Los investigadores de los Laboratorios de Abbott, Lilly y Upjohn aislaron un mieroorganismo en una muestra del suelo de las islas Filipinas, e1 cual produce un antibiótico de extraordinarias propiedades, enteramente diferente de los antibióticos aislados hasta ahora, de amplio campo de acción antibacteriana y enteramente atóxico.

Pantomicina. Es la marca registrada de Abbott para la eritromicina. La forma de presentación comercial es en tabletas de 100 miligramos cada una, protegidas de cubierta entérica, que contiene como ingrediente principal una sustancial química de Pralato-acetato de celulosa.

Dosis recomendada para adultos de 0,80 a 2 grs. y para niños 30 miligramos por kilogramo de peso, en las 24 horas.

Experiencia clínica. Las primeras experiencias clínicas con este antibiotico corresponden a Mc Guire, J. M. y col. (1952) ; Heiman, F. R.; Wellman, W. B. y Geraci, Staff Meet, Mayo Clin. (1952). Height, T. H. y Finland, M., New Engl., J. Med. (1952).

Desde que se publicaron los trabajos de estos autores, la eritromicina se ha empezado a usar en unas 75 clínicas importantes de los EE. UU.

Hasta el momento que escribimos el presente trabajo no ha llegado a nuestras manos literatura acerca del tratamiento de la coqueluche con este antibiótico. Por esta razón no se consiguen datos al respecto.

\section{Material}

Nuestro material de estudio comprende un grupo de 20 niños sin ninguna medicación antes de ser sometidos a la terapia eritromicínica. De éstos, 9 son lactantes menores de 1 año y 11 totalizan un promedio de 4 años. El tiempo de enfermedad antes de su hospitalización fluctúa entre 3 días como mínimo y 21 como máximo; es decir, con un promedio de 8,8 dias de iniciación.

Antes del tratamiento. Entre las modalidades clínicas más saltantes se ha constatado lo siguiente: el $100 \%$ se hospitalizaron febriles, sin que existiera en ninguno de ellos compromiso pulmonar, salvo el caso 12 , que ingresa con bronconetumonía. El cultivo al Hemophilus Pertussis resultó positivo en los 20 niños. El $30 \%$ de los enfermos presentaba alrededor de 20 quintas entre el día $\mathrm{y}$ la noche, con vómito en la mayoría de los accesos. Anorexia en el $90 \%$ y decainiento en el $35 \%$ de los casos. La leucocitosis era la regla y sobrepasaba la cifra de 15.000 . La velocidad de sedimentación por encima de 15 , en el $90 \%$ de los enfermos.

Tratamiento. Para conseguir la modificación de estos síntomas y la normalización del hemograma y la cifra de la eritrosedimentación, ha sido necesario emplear eritromicina a las dosis de $\mathbf{3 0}$ miligramos como mínimo y 66,6 miligramos como máximo, con una dosis total promedio de 5,2 gramos, durante un promedio de 14,6 días de tratamiento.

Durante el tratamiento los casos $5,6,7 \mathrm{y}$ 11 , menores de 1 año, hicieron una complicación broncopulmonar, falleciendo el segundo a los 8 días después de haber recibi. do 2,4 grs. de eritromicina. En este caso las quintas apenas se modificaron en intensidad; la eritrosedimentación se mantuvo con ligeras variaciones; y la leucocitosis, que al comienzo fué de 19,800 , en el $7^{\circ}$ día bajó a 7,300 .

El caso 5 a los 12 días de tratamiento se complica de bronconeumonía después de haber recibido 3,6 grs. del antibiótico, logrando salir airoso de esta complicación con el auxilio de la aureomicina (450 miligramos). Durante el empleo de la eritremicina no desaparecieron las quintas; el hemograma se normalizó a los 7 días; y la velocidad de sedimentación se mantuvo alta hasta los 11 dias.

El caso 7 se complica de bronconeumonía a los 7 días, después de haber recibido 2,8 grs. de eritromicina en 8 días. Se logra su curación con aureomicina (525 miligramos). Durante el tratamiento eritromicínico no se modificaron las quintas; no cedí la fiebre; no se normalizó el hemograma ni la eritrosedimentación.

El caso 11 a los 4 días ínicia su complicación bronconeumónica, recibiendo eritromicina a la dosis de 31,5 miligramos por kilo de peso durante 2 días; como quiera que no se consigue mejoria, se le administra aureomicina, que tampoco logra dominar la gravedad del enfermo. En vista de este fracaso se le administra nuevamente eritromicina, pero subiendo la dosis hasta 
42 miligramos por kilo de peso, con lo que se consigue la curación del enfermo en 6 días, totalizando una dosis de 3 gramos. La leucocitosis de 25,600 bajó a la cifra normal a los 3 días de este nuevo tratamiento, lo mismo que la velocidad de sedimentación. Alta a los 17 días.

El caso 12, que desde su ingreso presentara una complicación bronconeumónica, fallece a los 2 días de tratamiento con eritromicina.

En los 15 casos que durante el tratamiento no presentaron ninguna complicación, nuestras observaciones clínicas pueden resumirse en la forma siguiente: desaparición de la temperatura en un promedio de 6 días; desaparición de las quintas a los 15 días; mejoría clínica a los 7 días; velocidad de sedimentación a los 16 días; normaliza.

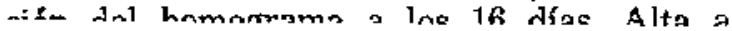

los 22 días. Datos que se aprecian en el gráfico $N^{9} 1$.

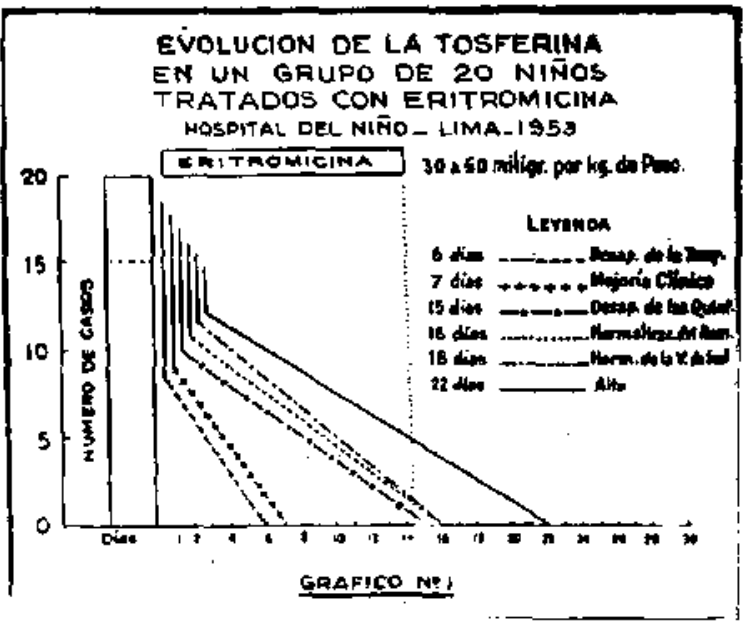


En ninguno de nuestros casos se present6 intolerancia al antibiótico, salvo un ligero rash en el caso 4 , de banal importancia.

Para dar mayor claridad en el cuadro $\mathrm{N}^{\circ} 1$ resumimos detalladamente nuestras observaciones.

\section{Resultados}

Aun cuando la casuística que presentamos es poco numerosa para deducir conclusiones definitivas, en cambio, es bastante significativa para formarnos un juicio más o menos exacto acerca de la acción de este nuevo antibiótico en los enfermos de tos ferina que hemos tratado.

De los 20 casos tratados con eritromicina 18 evolucionaron hacia la curación después de una estadía hospitalaria de 22,6 días como promedio, y 2 fallecieron. En los 5 casos complicados de bronconeumonía no se vió sino en un caso la acción favorable del antibiótico; en los 4 restantes su acción fué nula. También se puede afirmar que dicho antibiótico no previene las complicaciones, ya que en pleno trat (miento se hizo presente el compromiso broncopulmonar. En 5 casos se reagudizaron los síntomas.

La evolución favorable se ha obtenido empleando por vía oral una dosis de antibiótico entre $\mathbf{3 0}$ miligramos y $\mathbf{5 0}$ miligramos por kilo de peso, en un tiempo promedio de 14,6 dias, durante los cuales se logró la desaparición de las quintas, la mejoría del estado general y poco después la normalización del hemograma y el descenso de la cifra de eritrosedimentación (ver cuadro No 2).

\begin{tabular}{|c|c|c|c|c|c|c|c|c|c|}
\hline EP & 20 & $\begin{array}{l}\text { SULTA } \\
\text { CON } \\
\text { VIÑOS } \\
\text { HOSPITA }\end{array}$ & $\begin{array}{l}\text { ADO DE } \\
\text { ERI } \\
\text { ENFE } \\
\text { DOEL }\end{array}$ & $\begin{array}{l}\text { EL TR } \\
\text { TRO } \\
\text { RMO } \\
\text { INOA- }\end{array}$ & $\begin{array}{l}\text { RAT, } \\
\text { OMIC } \\
\text { S. DI } \\
\text { LIMA }\end{array}$ & $\begin{array}{l}\text { RESULTADO DEL TRATAMIENTC } \\
\text { CON ERITROMICINA }\end{array}$ & $\begin{array}{l}\text { AIEN } \\
\text { NA } \\
\text { TOSF } \\
\text { IOSS. }\end{array}$ & ERINA & \\
\hline \multirow[t]{2}{*}{$\begin{array}{l}\text { Vo de } \\
\text { Casos }\end{array}$} & \multirow{2}{*}{$\begin{array}{l}\text { Oios de } \\
\text { Enf. } \\
\text { sndes del } \\
\text { Tratem } \\
\text { Promed }\end{array}$} & \multirow{2}{*}{$\begin{array}{c}\text { Dias } \\
\text { en } \\
\text { Tratsm. } \\
\text { Dromed. }\end{array}$} & \multirow{2}{*}{$\begin{array}{c}\text { Dosis } \\
\text { pas Kg. } \\
\text { de Peso } \\
\text { Dis }\end{array}$} & \multirow{2}{*}{$\begin{array}{l}\text { Dosis } \\
\text { Tolsi } \\
\text { Promed. }\end{array}$} & \multirow{2}{*}{\multicolumn{2}{|c|}{\begin{tabular}{|l|l|} 
tandirión \\
c. & f. \\
\end{tabular}}} & \multirow{2}{*}{$\begin{array}{l}\text { Alta } \\
\text { ois } \\
\text { Promet }\end{array}$} & \multicolumn{2}{|c|}{ Resultadost } \\
\hline & & & & & & & & 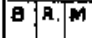 & 5 Nula \\
\hline 20 & 8.8 & 14.6 & $30.50 \mathrm{mg}$ & $5.2 \mathrm{gr}$ & & 2. & 22.6 & \begin{tabular}{ll|l|l|l|l|}
5 & 10
\end{tabular} & 23 \\
\hline
\end{tabular}

De la justa apreciación de los datos obtenidos en el presente estudio, tenemos la impresión que los resultados obtenidos por nosotros se pueden resumir en la siguiente forma:

$\begin{array}{lrl}\text { Bueno } & \mathbf{5} & \mathbf{2 5} \% \\ \text { Regular } & 10 & \mathbf{5 0} \% \\ \text { Malo } & 2 & \mathbf{1 0} \% \\ \text { Nulo } & \mathbf{3} & \mathbf{1 5 \%}\end{array}$

\section{Conclusiones}

En 20 enfermos de tos ferina de $3 \frac{1}{2}$ meses hasta 10 años de edad tratados con exitromicina, se llega a las siguientes conclusiones:

$1^{\circ}$ Es manifiesta la acción bacteriostática in-vitro de la eritromicina sobre el hemophilus pertussis, fase 1 , acción que se ejerce desde una concentración que varía entre 0,1 y $0,5 \mathrm{mcg} . / \mathrm{cm}^{3}$ a $35^{\circ} \mathrm{C}$ en 48 horas.

$2^{\circ}$ Se han obtenido buenos resultados por vía oral, empleando las dosis entre 30 y 50 miligramos por kilo de peso, en 24 horas.

$3^{\circ}$ Se estima en 14,6 días promedio el tiempo de tratamiento ininterrumpido, para la curación clínica y hematológica.

$4^{9}$ La reagudización de.los sfntomas se presenta en el $20 \%$ de los casos.

$5^{\circ}$ Es una droga útil; y su bondad se muestra indiscutible sólo en el $25 \%$ de los casos.

$6^{\circ}$ En el $95 \%$ de los casos no existe intolerancia a la droga.

$7^{\circ}$ No previene las complicaciones broncopulmonares.

$8^{\circ}$ En el $80 \%$ de los casos, la acción de la eritromicina es nula en las complicaciones broncopulmonares.

$9^{9}$ Para mejorar los resultados obtenidos debe ampliarse esta experiencia con mayor número de casos, ensayando nuevas dosis de tratamiento.

\section{Conclusions}

In 20 pertussis patients from $3 \frac{1}{2}$ months to 10 years of age, treated with erithromycin, the following conclusions have been reached:

The bacteriostatic in-vitro action of the erithromycin on the hemophilus pertussis phase $I$ is manifest. This action is noted from a concentration that varies between 0,1 and $0,5 \mathrm{mcg} . / \mathrm{cm}^{3}$ at $35^{\circ} \mathrm{C}$ in 48 hours.

Good results have been obtained by oral administration using a dose between $\mathbf{3 0}$ and $\mathbf{5 0}$ miligrams per kilo of weight in 24 hours.

14,6 days is estimated as the average time of uninterrupted treatment for the clinical and hematological cure. 
The relapse of symptoms is present in $20 \%$ of the cases.

It is a useful drug; and its usefulness is indisputably demonstrated in $25 \%$ of the cases.

In $95 \%$ of the cases there is no intolerance to the drug.

It does not prevent broncopulmonary complications and when these are present in $80 \%$ of cases it has no effect.

The author recommends further clinical investigation to improve the present results of treatment.

\section{HHLIOGIRAFLA}

]. GALAFELL, GILBERT Y JUFRESA ROCA, FRAN. C.ISCO-Tratamiento de la tos ferina con aureo. micina y cloromicetina. Acta Pediátrica Española 11: 369, No 123, I953.

2. PAYNE, EUCENE H. y col-Pettussis tteated with cloranphenicol. J. A. M. A. 141: 1298, 1950.

3. MENEGHELlo, J. y GALlo, A-Tratamiento ambulatorio con cloromicetina en un grupo de nifios con tos ferina. Rev. Chil. Ed. 22: 195, 1951.

4. LO7ANO, TEOBALDO-Estrepromicina en coqueluche. Tesis Br. 1947. Facul. Méd. Lima.

5. CAMPOS, HUBI-Acrovol de cstreptomicina en el tratamiento de la coqueluche. Tesis Br. 1950, Fa* cult Med. Lima.

6. POZ7I, ESCOT.-Vitamina $\mathbf{k}$ en roqueluche, 1951. Facul. Med. Lima.

7. VALVERDE, B.-Yruebas in-vitro y tratamiento de la coqueluche con terranticina. Tesis B:. 1950. Facul. Med. Lima.

8. DURAN LAZARTE, B.-Prucbas ill-ritro y trata. miento de la coqueluche con auramicina. Tesis Br. 1951. Facul. Med. Lima. 